Jurnal Akses Pengabdian Indonesia Vol 3 No 1: 48-53, 2018

\title{
Peningkatan Produktivitas Biting, Dupa, Dan Sayur Organik Di Kecamatan Wagir Kabupaten Malang
}

\author{
Ninik Indawati ${ }^{1}$, Endi Sarwoko ${ }^{2}$, Sri Umi Mintarti $W^{3}$, Nila Restu Wardani ${ }^{4}$ \\ ${ }^{1,2,4}$ Universitas Kanjuruhan Malang \\ ${ }^{3}$ Universitas Negeri Malang

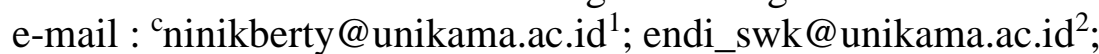 \\ sriumi_mintarti@yahoo.co.id ${ }^{3}$; nilarestu@unikama.ac.id ${ }^{4}$
}

\begin{abstract}
Abstrak
Desa Dalisodo dan Pandanrejo berada di Kecamatan Wagir Kabupaten Malang sangat potensial dalam mengembangkan usaha biting dan dupa, yang mayoritas masih diproduksi secara manual. Permintaan terhadap produk biting dan dupa dari Pulau Bali dan Lombok sangat tinggi. Metode pelaksanaan melalui tahapan identifikasi dan pengelompokan jenis usaha di desa Dalisodo dan desa Pandanrejo, manajemen usaha, pengemasan, pemasaran, administrasi keuangan, dan perpajakan, sosialisasi kebersihan lingkungan, serta pelatihan pertanian organik bagi masyarakat petani, praktik menanam tanaman sayur organik sampai pada panennya, serta monitoring dan pendampingan yang dilakukan setelah pelaksanaan pelatihan. Hasil disampaikan bahwa produktivitas biting sebagai bahan pembuatan dupa meningkat setelah menggunakan mesin gesek yaitu $140 \%$, sebelum menggunakan mesin gesek hanya $5 \mathrm{~kg} / \mathrm{hari}$ dan setelah menggunakan mesin gesek meningkat menjadi $12 \mathrm{~kg} /$ hari. Produktivitas dupa secara manual hanya $7 \mathrm{~kg} / \mathrm{hari}$ dan setelah menggunakan mesin mixer meningkat menjadi $20 \mathrm{~kg} / \mathrm{hari}$. Sayur organik yang dikembangkan yaitu bayam merah, bayam hijau, selat, kecai, cabai, tomat, terong, sawi. Tim pengabdi telah berkoordinasi dengan perangkat desa, kantor dinas koperasi, usaha mikro kabupaten Malang, sasaran program tim pengabdi tercapai, pendapatan masyarakat mengalami peningkatan kuantitas dan kualitas produk untuk dipasarkan serta tanaman organik menjadi salah satu budidaya masyarakat untuk dikonsumsi sebagai makanan sehat dalam keluarga, dan nantinya menjadi desa wisata.
\end{abstract}

Kata Kunci: biting; dupa; sayur organic

\section{PENDAHULUAN}

Kecamatan Wagir terletak di bagian tengah utara Kabupaten Malang. Kawasan iniberada di lereng Gunung Kawi dengan suhu berkisar 11-25 Celcius. Kecamatan Wagir yang berbatasan langsung dengan Kota Malang memiliki posisi yang cukup strategis, ditandai dengan semakin ramainya jalur transportasi utara maupun selatan yang melalui Kecamatan Wagir. Luas kawasan Kecamatan Wagir secara keseluruhan adalah $75,43 \mathrm{~km} 2$ atau $2,53 \%$ dari total luas Kabupaten Malang. Dari segi luas wilayah tersebut, jika diurutkan maka kecamatan Wagir berada pada urutan ke-17 dari 33 kecamatan di Kabupaten Malang. Kondisi topografi Kecamatan Wagir merupakan daerah datar dan perbukitan pada ketinggian 474 meter di atas permukaan laut. Dari ibukota propinsi Surabaya, kecamatan Wagir dapat ditempuh selama kurang lebih 3 jam.

Kecamatan Wagir terdiri atas 12 desa yaitu desa Dalisodo, desa Gondowangi, desa 
Jedong, desa Mendalanwangi, desa Pandan landung, desa Pandanrejo, desa Parangargo, desa Petungsewu, desa Sidorahayu, desa Sitirejo, desa Sukodadi, dan desa Sumbersuko. Dengan total penduduk 71.688 jiwa mayoritas penduduk di kecamatan ini memiliki mata pencaharian sebagai petani, yakni sebesar $65 \%$. Sementara sisanya $20 \%$ sebagai pengolah kebun, $10 \%$ sebagai PNS, dan buruh lepas sebesar $5 \%$.

Salah satu potensi alam yang menarik di kecamatan Wagir adalah adanya kondisi alam dengan perbukitan yang sejuk dan memiliki udara yang masih bersih. Obyek wisata yang terletak di Kecamatan Wagir yang sering menarik minat wisatawan yaitu: Wanawisata Air terjun Coban Glotak di desa Dalisodo, Pekuburan tua di desa Sumberpang, sumber mata air Gunung Katu di desa Sumberpang, Pemandian kolam renang di desa Petungsewu, bunder holtikultura di desa Sidorahayu, pemandian tirta alam desa Sidorahayu, taman buah bunton di dusun Bunton, dan wisata pembuatan dupa di desa Dalisodo. Selain potensi di bidang Pariwisata, beberapa desa di Kecamatan Wagir juga memiliki industri kecil pembuatan biting dan dupa wangi yang juga memungkinkan untuk dikembangkan. Mempertimbangkan kekayaan sumber daya alam tersebut, jika ditangani dengan serius, potensi wisata dan industri di Kecamatan Wagir dapat dijadikan sebagai trigger atau pemicu bagi pengembangan desa untuk membantu menyelesaikan masalah kemiskinan, dimana menurut data kecamatan Wagir pada tahun 2015 menunjukkan bahwa $30 \%$ KK di kecamatan Wagir masih tergolong di dalam kategori miskin.

Dari keduabelas desa yang berada di dalam wilayah kecamatan Wagir, desa Dalisodo dan desa Pandanrejo merupakan dua desa yang memiliki potensi paling besar untuk dikembangkan. Kedua desa tersebut memiliki pemandangan alam yang indah. Selain potensi wisata yang dimiliki oleh desa Dalisodo dan desa Pandanrejo, potensi lain yang sedang dikembangkan adalah potensi di bidang pertanian tanaman sayur organik dan industri pembuatan biting dan dupa wangi. Hal ini disebabkan karena selain bertani, penduduk di desa Dalisodo menekuni industri pembuatan biting dan dupa yang semula dilakukan dengan cara yang masih tradisional, namun saat ini sudah mengalami perubahan walau belum maksimal.Namun demikian berbagai macam permasalahan masih dihadapi oleh kedua desa tersebut sehingga potensi-potensi tersebut belum tertangani secara maksimal.

\section{PERMASALAHAN MITRA}

Permasalahan yang dihadapi masyarakat desa Dalisodo dan desa Pandanrejo Kecamatan Wagir Kabupaten Malang saat ini antara lain :

1. Peralatan masyarakat pengrajin biting sangat sederhana, sehingga produksi terbatas dan diperlukan alih teknologi yaitu alat gesek berupa alat kayu yang menggunakan tenaga listrik/dinamo

2. Pengelolaan keuangan sangat sederhana, sehingga diperlukan manajemen keuangan sederhana

3. Sebanyak $21.566 \mathrm{KK}$ atau $30 \%$ dari keseluruhan KK di kecamatan Wagir tergolong KK miskin

4. Dengan total penduduk 71.688 jiwa mayoritas penduduk di kecamatan ini memiliki mata pencaharian sebagai petani, yakni sebesar 65\%, sehingga pertanian sayur organik merupakan salah satu solusi untuk hidup sehat 


\section{TARGET LUARAN}

Program PKW desa Dalisodo dan desa Pandanrejo Kecamatan Wagir Kabupaten Malang menekankan pada :

1. Teridentifikasinya dan terbentuknya kelompok usaha kecil pembuatan biting dan dupa dan pertanian organik

2. Terbentuknya pusat pelatihan kewirausahaan

3. Meningkatnya manajemen usaha, pemasaran, pengemasan produk biting dan dupa wangi, pencatatan administrasi dan keuangan sederhana

4. Terciptanya lingkungan bersih dan sehat

5. Terbentuknya kelompok usaha dengan kemasan menarik dan perluasan pemasaran sehingga memiliki icon sebagai desa wisata.

6. Tersusunnya buku panduan pertanian organik ber ISBN

7. Tersusunnya buku ajar manajemen usaha, pemasaran, dan pengemasan produk ber ISBN

\section{METODE PELAKSANAAN}

Program-program yang ditawarkan dengan mempertimbangkan permasalahan yang muncul, potensi lokal di desa Dalisodo dan Pandanrejo yakni pengembangan di bidang industri kecil pembuatan biting dan dupa dan juga mempertimbangkan RPJMD Kabupaten Malang yang memprioritaskan pengentasan kemiskinan dan penciptaan lapangan kerja yang akan dilaksanakan dalam kurun waktu 3 tahun.

\section{A. Metode yang dilaksanakan}

Rancangan evaluasi kegiatan, tahapan kegiatan Program Kemitraan Wilayah antara PT-Pemda-CSR beserta pencapaian indikator keberhasilan/solusi terhadap permasalahan mitra diuraikan sebagai berikut :

1. Pelatihan Manajemen Usaha

2. Pelatihan Pengemasan Produk
3. Pelatihan Pemasaran Produk

4. Pelatihaan Pencatatan Administrasi dan Keuangan Sederhana

5. Pelatihan Perpajakan Bagi Usaha Kecil

6. Pelatihan Pertanian Organik Bagi Masyarakat Petani

7. Praktik dan pendampingan penanaman Sayuran Organik

8. Sosialisasi kebersihan lingkungan

9. Evaluasi dan monitoring

\section{B. Partisipasi mitra dalam pelaksanaan program}

Partisipasi mitra dalam pelaksanaan program PKW sangat menentukan keberhasilan dari program dan keberlanjutannya. Beberapa caraa ayang bisa dilakukan agar mitra berpartisipasi aktif dalam pelaksanaan program PKWini adalah :

1. Pelibatan dosen selain tim pengabdi dalam pelaksanaan program dapat memotivasi peserta, baik terhadap peserta pada pelatihan pertanian organik maupun terhadap peserta pelatihan lainnya.

2. Pelibatan mahasiswa sebagai motivator.

3. Kunjungan lapang oleh tim pengabdi.

\section{Hasil Yang Dicapai}

Berdasarkan rancangan evaluasi kegiatan, tahapan kegiatan program kemitraan wilayah antara PT-Pemda-CSR beserta pencapaian indikator keberhasilan diuraikan sebagai berikut :

1. Pelatihan Manajemen Usaha

2. Pelatihan Pengemasan Produk

3. Pelatihan Pemasaran Produk

4. Pelatihaan Pencatatan Administrasi dan Keuangan Sederhana

5. Pelatihan Perpajakan Bagi Usaha Kecil

6. Pelatihan Pertanian Organik Bagi Masyarakat Petani 
7. Praktik penanaman Sayuran Organik

8. Sosialisasi kebersihan lingkungan
9. Evaluasi dan monitoring
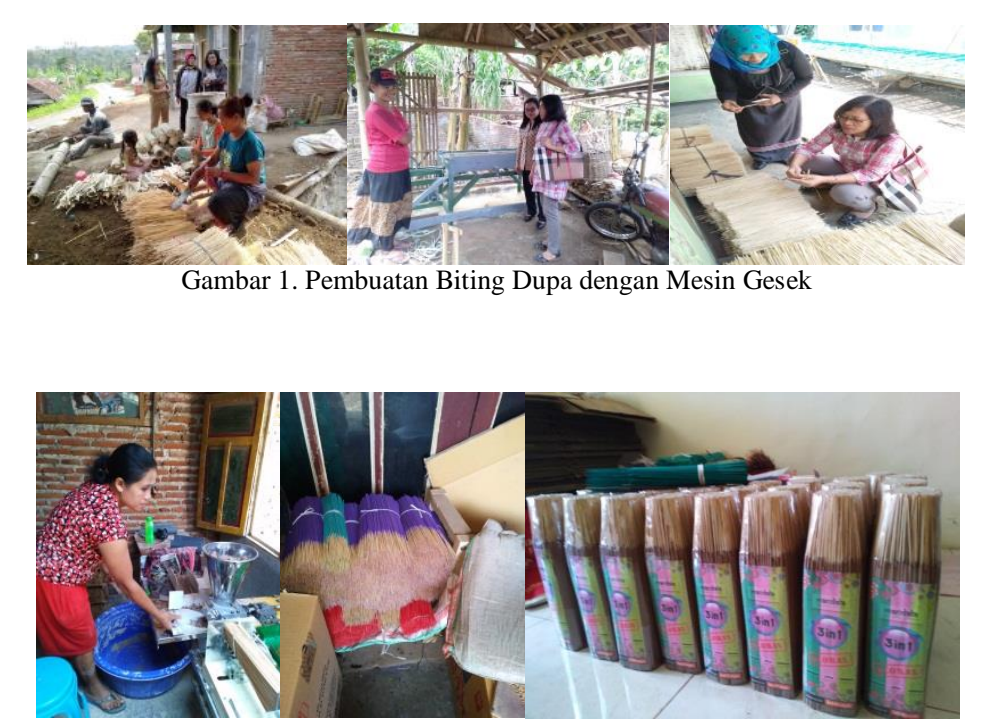

Gambar 2. Pembuatan Dupa Aneka Warna dengan Mesin Mixer
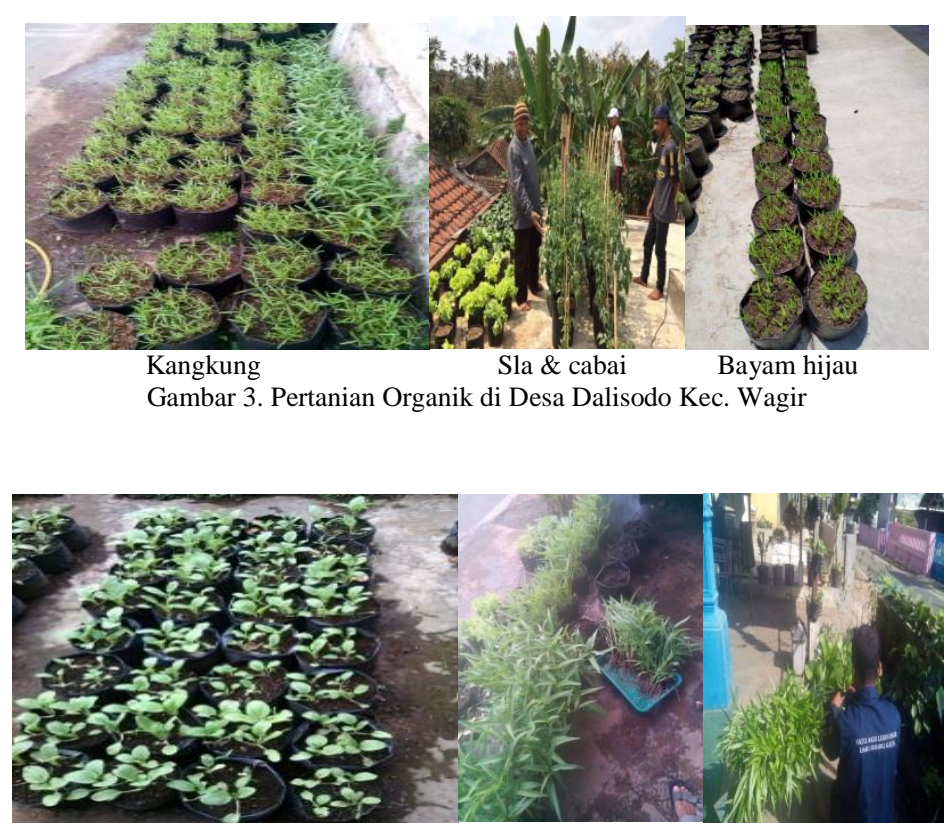

Sawi hijau

Kangkung

Bayam

Gambar 4. Pertanian Organik di Desa Pandanrejo Kec. Wagir

\section{Kontribusi Mitra}

Partisipasi mitra dalam pelaksanaan program pengabdian masyarakat sangat menentukan keberhasilan dari program dan keberlanjutannya. Beberapa cara yang bisa dilakukan agar mitra berpartisipasi aktif yaitu:

1. Pelibatan dosen selain tim pengabdi dalam pelaksanaan program dapat memotivasi peserta. 
2. Pelibatan mahasiswa sebagai motivator

Program pengabdian masyarakat ini merupakan kerjasamaantara PT-Pemda-CSR telah berjalan sesuai dengan rencana yang telah disusun. Fokus pada tahun pertama adalah pada identifikasi masalah pada wilayah desa mitra dan melaksanakan program sesuai metode yang telah ditetapkan, serta dilaksanakan secara bertahap, dan berkelanjutan. Melaksanakan pendampingan secara berkelanjutan karena masyarakat dalam menjalankan usahanya hanya dengan bekal yang penting dapat uang dan tanpa memperhatikan faktor yang lain. Melaksanakan pendampingan secara aktif dari kantor dinas koperasi dan usaha mikro terkait perlunya ijin usaha dalam menjalankan usahanya (IUMK) bagi pelaku usaha mikro, dan adanya sosialisasi terhadap kecamatan dan desa terkait IUMK ternyata masyarakat awam tidak memahami apa yang dimaksud dengan IUMK.

Tabel 1. Peningkatan Produktivitas Biting, Dupa, dan Sayur Organik Di Kecamatan Wagir Kabupaten Malang

\begin{tabular}{lc}
\hline Kegiatan & Jumlah \\
\hline Produksi biting untuk dupa & \\
Sebelum menggunakan mesin gesek & $5 \mathrm{~kg} / \mathrm{hari}$ \\
Setelah menggunakan mesin gesek & $12 \mathrm{~kg} / \mathrm{hari}$ \\
Peningkatan produktivitas biting & $140 \%$ \\
Kualitas biting dengan mesin lebih halus & \\
\hline Produktivitas dupa & $7 \mathrm{~kg} / \mathrm{hari}$ \\
\hline Sebelum menggunakan mesin mixer & $20 \mathrm{~kg} / \mathrm{hari}$ \\
Setelah menggunakan mesin mixer & $285,7 \%$ \\
Peningkatan produktivitas dupa & \\
\hline Pertanian sayur organic & $0 \mathrm{~kg}$ \\
\hline Produktivitas sayur organik pada bulan pertama kegiatan & $9 \mathrm{~kg}$ \\
Produktivitas sayur organik pada bulan kedua kegiatan & $13 \mathrm{~kg}$ \\
Produktivitas sayur organik pada bulan ketiga kegiatan & $15 \mathrm{~kg}$ \\
Produktivitas sayur organik pada bulan keempat kegiatan & \\
& \\
\hline
\end{tabular}

\section{KESIMPULAN}

Produktivitas biting sebagai bahan Potensi Desa Dalisodo dan Pandanrejo pembuatan dupa mengalami peningkatan setelah menggunakan mesin gesek yaitu sebesar $140 \%$, dimana produktivitas biting sebelum menggunakan mesin gesek hanya 5 $\mathrm{kg} /$ hari dan setelah menggunakan mesin gesek meningkat menjadi $12 \mathrm{~kg} / \mathrm{hari}$. Produktivitas dupa secara manual hanya $7 \mathrm{~kg} /$ hari dan setelah menggunakan mesin mixer meningkat menjadi $20 \mathrm{~kg} /$ hari. Sayur organik yang dikembangkan berkaitan dengan produksi biting, dupa, dan sayur organik telah dikembangkan dan perlu kerjasama yang bersinergi antara pelaku usaha dengan Pemerintah Desa, Pemerintah Kabupaten Malang, dan pengabdi masyarakat dari universitas. Sinergitas ini bertujuan untuk meningkatkan produktivitas biting, dupa, dan sayur organik sebagai produk unggulan desa.

yaitu bayam merah, bayam hijau, selat, kecai, cabai, tomat, terong, sawi. 


\section{DAFTAR PUSTAKA}

Pemerintah Kabupaten Malang, 2011, Rencana Pembangunan Jangka Menengah Daerah Pemerintah Kabupaten Malang tahun 2010-2015.

Badan Pusat Statistik, 2012, Kecamatan Wagir dalam Angka Tahun 2010, BPS Kabupaten Malang, ISSN. 1403.35150. 